\title{
Characterization of microbial communities in marine surface sediments by terminal-restriction fragment length polymorphism (T-RFLP) analysis and quinone profiling
}

\author{
Hidetoshi Urakawa*, Tsutomu Yoshida, Masahiko Nishimura, Kouichi Ohwada**
}

Ocean Research Institute, University of Tokyo, 1-15-1 Minamidai, Nakano-ku, Tokyo 164-8639, Japan

\begin{abstract}
We characterized microbial communities from Japanese coastal sediments by using terminal-restriction fragment length polymorphism (T-RFLP) analysis and quinone profiling. Surface sediments (0 to $2 \mathrm{~cm}$ ) were collected from 5 different locations, Tokyo Bay (S1: water depth $15 \mathrm{~m}$ ), Sagami Bay (S2: 1520 m; S3: 1133 m), Suruga Bay (S4: 1290 m), and Nankai Trough (S5: 4023 m). The length of terminal-restriction fragments (T-RFs) was estimated by an automated DNA sequencer. The average fragment numbers (mean $\pm \mathrm{SD}$ ) estimated from the 3 separate restriction analyses (HhaI, $R s a \mathrm{I}$ and $M s p \mathrm{I}$ ) were $\mathrm{S} 1=74 \pm 6.2, \mathrm{~S} 2=28 \pm 4.6, \mathrm{~S} 3=27 \pm 6.2, \mathrm{~S} 4=73 \pm 4.0$, and $\mathrm{S} 5=35 \pm 2.1$. Sixteen quinone homologs were detected from S2, S3, S4 and S5, while 17 homologs were found from S1. Major differences in the quinone profiles among sampling sites were primarily related to the relative abundance of quinone homologs. However, the difference in homolog number did not contribute to the change of profile in each sampling site. The appearance and disappearance of quinone homologs were only seen in minor components. Community profiles from T-RFLP analysis revealed that the microbial population in Sagami Bay (S2 and S3) and Nankai Trough (S5) were similar (16.8 to $25.8 \%$ divergence). On the other hand, sediments from Sagami Bay (S2 and S3) were closely related to each other (13.9\% divergence), but quinone profiling of Nankai Trough sediment (S5) was not similar to those of Sagami Bay. It was assumed that this difference derived from different characteristics of the 2 techniques used. Thus, we found that the phylogenetic structures in S2, S3, and S5 were similar, but the relative abundance and physiological condition of the microbial populations was apparently different between Sagami Bay (S2 and S3) and Nankai Trough (S5). In this study, a combination of the methods T-RFLP and quinone profiling succeeded in characterizing the microbial community of marine sediments and it is likely that this approach will prove effective in future analyses of microbial communities in marine sediments.
\end{abstract}

KEY WORDS: Microbial community · Marine sediment · Terminal-restriction fragment length polymorphism (T-RFLP) analysis · Quinone profiling

Resale or republication not permitted without written consent of the publisher

\section{INTRODUCTION}

Benthic microbial communities play an important role in various important biogeochemical cycles in the marine ecosystem (Jørgensen 1982, Fenchel \& Finlay 1995). Marine sediments probably represent some of the most complex microbial habitats on earth: in these sediments, complex microbial communities arise through the merging of indigenous microorganisms present in

() Inter-Research 2001 marine sediments and external organisms transported from the water column or the terrestrial environment (Novitsky 1990). Although studying the microbial diversity and microbial population is essential for under-

${ }^{*}$ Present address: Civil and Environmental Engineering, University of Washington, 201 More Hall, Seattle, Washington 98195-2700, USA

** Present address: Faculty of Environmental and symbiotic Sciences, Prefectural University of Kumamoto, 3-1-100 Tsukide, Kumamoto 862-8502, Japan.

E-mail: ohwada@pu-kumamoto.ac.jp 
standing biogeochemical cycles, limited information is available because of the limitation of traditional cultivation techniques for assessing microbial diversity and population in marine sediments. It is well known that isolated microorganisms do not reflect the true composition and structure of communities. Today, new molecular techniques based on 16S rRNA enable us to analyze the microbial community without cultivation (Pace et al. 1986). One important approach is $16 \mathrm{~S}$ rDNA clone library analysis (Giovannoni et al. 1990), and several studies have been carried out on marine sediment communities using this technique (Gray \& Herwig 1996, Ravenschlag et al. 1999, Urakawa et al. 1999a) However, this technique is not sufficient for comparative studies involving several sampling locations or for monitoring population shifts, since it is time-consuming and labor-intensive. For these reasons, there is currently great interest in molecular fingerprinting techniques, such as denaturing gradient gel electrophoresis (DGGE), as effective approaches for evaluating large numbers of samples or monitoring population shifts (Muyzer et al. 1993). Attention has also recently focused on a relatively new genetic fingerprinting technique, terminal-restriction fragment length polymorphism (T-RFLP) analysis (AvanissAghajani et al. 1994, Liu et al. 1997, Marsh et al. 1998). The T-RFLP technique was used in this study because it is a robust and reproducible methodology for rapid analysis of microbial community structure in different samples (Osborn et al. 2000).

A different approach, analyzing biomarker compounds such as phospholipid fatty acid, has proved an effective method for determining the structure of microbial communities without cultivation (Rajendran et al. 1992, Findlay \& Watling 1998). The membrane lipid molecules, isoprenoid quinones, are also useful biomarkers in this case, because they are essential components of the respiratory or photosynthetic electron-transport systems of microorganisms and have been used as taxonomic tools because of the wide structural variation within their various taxonomic groups (Collins \& Jones 1981). In addition, quinone profiling has potential for evaluating a microbial community qualitatively and quantitatively (Hedrick \& White 1986, Hiraishi et al. 1998).

The present study was aimed at the characterization of whole microbial communities in the surface sediments. For shallow-water systems, as much as 30 to $70 \%$ of the total primary productivity may be deposited at the sediment-water interface. These surface sediments are the site of nutrient regeneration (Kemp $\&$ Boynton 1992) and the microbial activity of the sediment-water interface was several orders of magnitude greater than that of the overlying water and twice that of the sediment immediately below in Halifax Harbor,
Canada (Novitsky 1983). To gain a better understanding of the surficial microbial population, we used T-RFLP analysis as a genetic fingerprinting technique and quinone profiling as a chemotaxonomic technique.

\section{MATERIALS AND METHODS}

Study area. On 16 September 1998, sediment samples were collected from 5 locations in Tokyo Bay (S1: water depth $15 \mathrm{~m}$ ), Sagami Bay (S2: 1520 m; S3: $1133 \mathrm{~m})$, Suruga Bay (S4: $1290 \mathrm{~m})$, and Nankai Trough (S5: $4023 \mathrm{~m}$ ), Japan, by the RV 'Tansei-Maru' of the Ocean Research Institute, University of Tokyo (Fig. 1).

Tokyo Bay is located near the center of Honshu Island, Japan, and covers an area of about $1000 \mathrm{~km}^{2}$; mean depth is about $17 \mathrm{~m}$. Industrial and domestic waste from the large human population enters the bay mainly via 4 rivers. Excessive waste, compounded by a low water-exchange rate has caused marked eutrophication. As a result, remarkable growth in the phytoplankton population occurs during summer. Sagami Bay is located in the south-west of Tokyo Bay. There is a smooth exchange of water, since this bay is connected to the Pacific Ocean and the Kuroshio Current flows strongly offshore. The maximum depth of the bay is over $2000 \mathrm{~m}$. Suruga Bay is located in the west of Sagami Bay, its width and length are 56 and $60 \mathrm{~km}$, respectively. Steep underwater cliffs are present near the center of the bay, where the Suruga Trough is located, and the maximum depth of this area is over $2400 \mathrm{~m}$. Suruga Bay is also connected to the Pacific

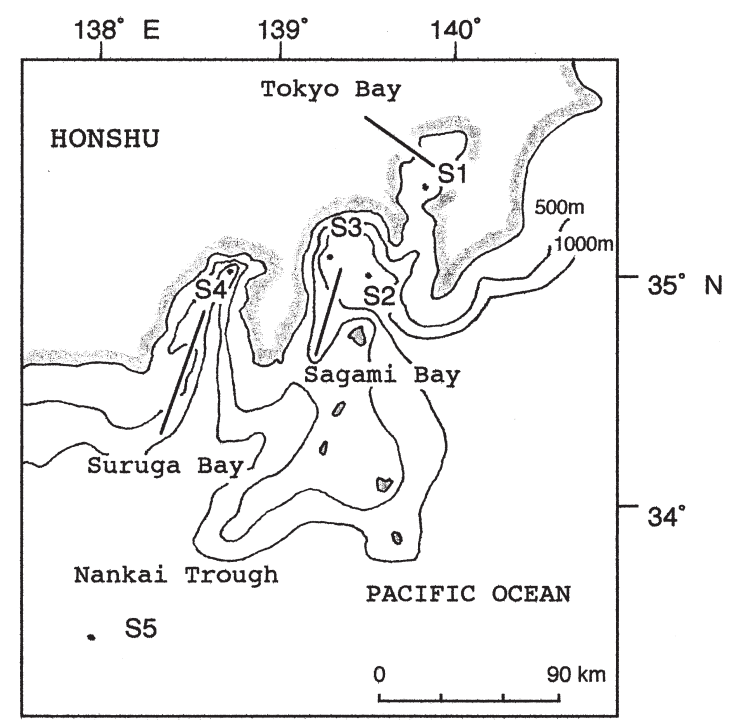

Fig. 1. Geographic positions of sampling sites. Sediment samples were collected from Tokyo Bay (S1: water depth $15 \mathrm{~m}$ ), Sagami Bay (S2: $1520 \mathrm{~m}$ and S3: $1133 \mathrm{~m})$, Suruga Bay (S4: $1290 \mathrm{~m}$ ) and Nankai Trough (S5: $4023 \mathrm{~m})$ 
Ocean, with the Kuroshio Current flowing offshore. The Nankai Trough is located in the south of Suruga Bay; the water depth here is over $4000 \mathrm{~m}$ (Coastal Oceanography Research Committee, The Oceanographical Society of Japan 1985).

Sampling procedure and physical and chemical characteristics of the sediment. Sediment samples were collected by a multiple-core sampler (Rigosha, Tokyo, Japan) without disturbance of the surface sediments or contamination from the surrounding seawater. The surface $2 \mathrm{~cm}$ of the cores (82 mm diameter) was aseptically sliced with a stainless steel core cutter (Rigosha). Sliced samples from 2 different cores were transferred to plastic bags, sealed with a thermosealer, and stored at $-20^{\circ} \mathrm{C}$ on board ship, and subsequently at $-80^{\circ} \mathrm{C}$ in the laboratory, until DNA and quinone extractions could be performed. Two further cores were used for physical and chemical analyses. The dry weight of each sample was measured after drying at $105^{\circ} \mathrm{C}$ for $48 \mathrm{~h}$. Ignition loss (IL) was measured after drying at $550^{\circ} \mathrm{C}$ for $6 \mathrm{~h}$. Redox potential was measured with an Eh electrode (RM-10P; TOA Electronics, Tokyo, Japan). The level of acid volatile sulfide-sulfur (AVS-S) was measured with a gas detector, Hedrotech-S (GasTec, Kanagawa, Japan).

DNA extraction and purification. The DNA extraction method described by Ueda et al. (1995) was used with some modifications. We mixed approximately $20 \mathrm{~g}$ of sediment with an equal volume of $120 \mathrm{mM}$ sodium phosphate buffer ( $\mathrm{pH} 8.0$ ) containing $5 \%$ SDS; the mixture was vigorously shaken in a plastic bottle for $40 \mathrm{~min}$ at $25^{\circ} \mathrm{C}$. Then $0.6 \mathrm{~cm}^{3}$ of the mixture was transferred to a $2 \mathrm{~cm}^{3}$ plastic tube and treated with 5 cycles of freezing in an ethanol-dry ice bath and thawing in a hotwater bath $\left(80^{\circ} \mathrm{C}\right)$. The lysate was purified with guanidine thiocyanate and chloroform using a SepaGene DNA extraction kit (Sanko Junyaku, Tokyo, Japan). Electrophoresis on a $0.7 \%$ agarose gel (agarose 1600; Wako Pure Chemicals, Osaka, Japan) in TAE buffer (40 mM Tris, $20 \mathrm{mM}$ acetate, 2 mM EDTA) was used to remove low-molecular-weight nucleic acids. DNA fragments larger than $15 \mathrm{~kb}$ were cut out and recovered with a GeneClean II kit (Bio101, Ja Jolla, CA, USA). The purity and concentration of DNA was verified with a spectrophotometer (Gene Quant II; AmershamPharmacia Biotech, Amersham Place, UK).

PCR amplification. The primers used for amplification of eubacterial 16S rDNA were 8f (5'-AGAGTTTG ATCCTGGCTCAG-3', Positions 8 to 27 of Escherichia coli 16S rRNA) and 926r (5'-CCGTCAATTCCTTTR(A and G)AGTTT-3', Positions 946 to 926) (Liu et al. 1997). For T-RFLP analysis, the forward primer, 8f, was labeled at the 5' end with Cy5 (Amersham-Pharmacia Biotech). The reaction mixture contained $1 \mu \mathrm{l}$ of template DNA, $5 \mu \mathrm{l}$ of $10 \times$ reaction buffer, $1.5 \mathrm{mM}$ of
$\mathrm{MgCl}_{2}, 200 \mu \mathrm{M}$ (each) of deoxynucleoside triphosphate (dNTP), $0.1 \mu \mathrm{M}$ (each) of primer, and 2.5U of rTaq DNA polymerase (Toyobo, Osaka, Japan) in a final volume of $50 \mu \mathrm{l}$. DNA amplification was performed in a Model PTC-100 thermal cycler (MJ Research, Watertown, MA, USA) with the following profile: initial denaturation for 2 min at $94^{\circ} \mathrm{C} ; 35$ cycles of denaturation (1 min at $\left.94^{\circ} \mathrm{C}\right)$, annealing $\left(1.5 \mathrm{~min}\right.$ at $\left.45^{\circ} \mathrm{C}\right)$, and extension $\left(1 \mathrm{~min}\right.$ at $\left.72^{\circ} \mathrm{C}\right)$; and a final extension at $72^{\circ} \mathrm{C}$ for $3 \mathrm{~min}$. The success and yield of each amplification reaction were determined by electrophoresis on a $1 \%$ agarose gel in TAE buffer with 2 to $5 \mu$ aliquots of PCR products. The purity and concentration of DNA was examined using a spectrophotometer (Gene Quant II; Amersham-Pharmacia Biotech).

Terminal-restriction fragment length polymorphism analysis. After purification with a Microcon-100 micro-concentrator (Amicon, Millipore, Redford, MA, USA), approximately $4 \mu \mathrm{g}$ of purified DNA was digested with endonucleases HhaI (12U), RsaI (12U) and MspI (16U) (Toyobo). The digestions were separately performed in a total volume of $10 \mu \mathrm{l}$ at $37^{\circ} \mathrm{C}$ for $6 \mathrm{~h}$. Aliquots $(7 \mu \mathrm{l})$ of the digested samples were mixed with $5 \mu$ l of loading dye, including formamide, and $3 \mu \mathrm{l}$ of the mixture were used for loading to a polyacrylamide gel (6\%) (Long Ranger gel solution; FMC BioProducts, Rockland, ME, USA). The mixtures were denatured at $95^{\circ} \mathrm{C}$ for $3 \mathrm{~min}$ and then chilled on ice. The length of the terminal-restriction fragments (T-RFs) from the amplified rDNA products was estimated using the size standard (ALF sizer 50-500; Amersham-Pharmacia Biotech). 16S rDNA from Escherichia coli was amplified by using 2 primer pairs as additional size standards. The forward primer in both cases was $8 f$. The reverse primers used were 685r2 (5'-TCTACGCATTTCACY(C and T)GCTAC-3', Positions 705 to 685 of E. coli 16S rRNA) (Lane 1991) and 926r. The amplified fragments of 697 and $919 \mathrm{bp}$ were diluted 10 times and $2 \mu \mathrm{l}$ of each PCR product was mixed with the size standard $(2 \mu \mathrm{l})$ and loading dye $(3 \mu \mathrm{l})$. The mixtures were denatured at $94^{\circ} \mathrm{C}$ for $3 \mathrm{~min}$ and immediately chilled on ice. Aliquots $(5 \mu \mathrm{l})$ of samples were loaded into each well and the size standards were loaded on either side of the sample-containing lanes. Electrophoresis on a polyacrylamide gel was carried out with an automated DNA sequencer (ALF EXPRESS DNA Sequencer; Amersham-Pharmacia Biotech) for $16 \mathrm{~h}$ under the following conditions: $1500 \mathrm{~V}, 55 \mathrm{~mA}$, and $55^{\circ} \mathrm{C}$. After electrophoresis, the sizes of the 5'-terminalrestriction fragments and the intensities (= peak areas) were calculated with the AlleleLinks Version 1.00 (Amersham-Pharmacia Biotech). The accuracy of size calling between replicates was $\pm 1 \mathrm{bp}$. Reproducibility of the T-RFLP analysis was examined using duplicate PCR products of surface sediments from S1, S2 and S5. 
Extraction and fractionation of quinones. The extraction and fractionation of quinones followed the method of Hiraishi et al. $(1996,1998)$. The frozen sediment samples (approximately $15 \mathrm{~g}$ of wet sediments) were washed with 3 vol. of $50 \mathrm{mM}$ phosphate buffer containing $1 \mathrm{mM}$ ferricyanide ( $\mathrm{pH}$ 6.8). The sediments were resuspended in this buffer to a total volume of $10 \mathrm{ml}$ and centrifuged at $10000 \times \mathrm{g}$ for $10 \mathrm{~min}$ at $20^{\circ} \mathrm{C}$. The samples were then sonicated for $1 \mathrm{~min}(20 \mathrm{kHz}$, $100 \mathrm{~W})$ in $2.5 \mathrm{vol}$. of chloroform-methanol (2:1 vol./vol.) and centrifuged at $5000 \times g$ for $10 \mathrm{~min}$ at $20^{\circ} \mathrm{C}$. The aqueous phase was removed and the chloroform-methanol layer was collected. Quinones were recovered by precipitation 3 times with 3 vol. of chloroform-methanol (2:1 vol./vol.), evaporated in a vacuum at $<35^{\circ} \mathrm{C}$, and reextracted 3 times with n-hexane-water (1:1 vol./vol.). This crude quinone extract in n-hexane was concentrated in a vacuum and applied to a Sep-Pak Plus Silica column (Waters, Milford, MA, USA) and then eluted once with $20 \mathrm{ml}$ of n-hexane-diethyl ether (99:1 vol./vol.) for the menaquinone (MK) fraction and a second time with $20 \mathrm{ml}$ of $\mathrm{n}$-hexane-diethyl ether (90:10 vol./vol.) for the ubiquinone (UQ) fraction, at a flow rate of $20 \mathrm{ml} \mathrm{min}^{-1}$. Each fraction was evaporated and then dissolved in $100 \mu \mathrm{l}$ of acetone. The presence of MKs and UQs in these fractions was confirmed by a high-performance liquid chromatography (HPLC) (System Gold Noubou; Beckman, Tokyo, Japan). The $\mathrm{C}_{18}$ column $\left(\mathrm{C}_{18}\right.$ ODS 4.6 i.d. $\times 250 \mathrm{~mm}$; Du Pont, Wilmington, DE, USA) was used in a column oven (CO-965 Jasco) at $30^{\circ} \mathrm{C}$. Quinone components were eluted with a mixture of methanol/isopropyl ether (5:1 vol./vol.) at a flow rate of $1 \mathrm{ml} \mathrm{min}^{-1}$.

Identification and quantification of quinones. Quinone components were identified by a photodiode array detector (Beckman) and some quinone standards. The detector signal was monitored at 275 and $283 \mathrm{~nm}$ for UQs and at 255 and $270 \mathrm{~nm}$ for components of the MK fraction, with on-line scanning at wavelengths from 220 to $350 \mathrm{~nm}$. Standard UQs (Wako Pure Chemical Industries) and phylloquinone (Vitamin $\mathrm{K}_{1}$ ) (Sigma, St. Louis, MO, USA) were used. Additional standards were prepared from known bacterial species (Vibrio alginolyticus NC MB 1903 ${ }^{\mathrm{T}}$, Synechococcus leopoliensis IAM M-6, and Shewanella putrefaciens IAM $12079^{\mathrm{T}}$ ) and an activated sludge sample (gift from A. Hiraishi, Toyohashi University of Technology). Relative peak-area ratios between benzoquinones and naphthoquinones were calculated according to their respective extinction coefficients (Kröger 1978). Peaks smaller than $0.01 \%$ of the total peak area were eliminated from analysis.

UQs, plastoquinones (PQs) and MKs with $n$ isoprene units in their side chains were designated Q-n, PQ- $n$, and MK- $n$, respectively. Partially hydrogenated MKs were designated MK- $n(\mathrm{H} x)$, where $x$ indicates the number of hydrogen atoms saturating the side chain.

Numerical analysis. We used 3 different parameters, the microbial divergence index $(M D q)$ and the bioenergetic divergence index $(B D q)$ for quinone profiling, and the divergence index $(D)$ for quinone and T-RFLP analysis (Iwasaki \& Hiraishi 1998, Hiraishi et al. 1999). $M D q$ is given by:

$$
M D q=\left(\sum_{k=1}^{n} \sqrt{x_{k}}\right)^{2}
$$

where $x_{k}$ is $\geq 0.001$, and $x_{k}$ indicates the molar ratio of the content of the quinone homolog $k$ to the total quinone content. $B D q$ is given by:

$$
B D q=\left(\sqrt{U Q}+\sqrt{P Q+K_{1}}+\sqrt{M K}\right)^{2}
$$

where $U Q_{1}\left(P Q+K_{1}\right), M K \geq 0.001$, and $U Q, P Q, K_{1}$, and $M K$ indicate the molar fractions of UQs, $\mathrm{PQs}, \mathrm{K}_{1}$, and MKs (plus their derivatives), respectively, compared to the total quinone content. $D$ is given by:

$$
D(i, j)=\frac{1}{2} \sum_{k=1}^{n}\left|x_{i k}-x_{j k}\right|
$$

where $x_{i k}, x_{j k}$ is $\geq 0.01, \sum x_{i k}=\sum x_{j k}=100$, and $x_{i k}$ and $x_{j k}$ indicate the levels (expressed as percent of moles) of the quinone homolog $k$ or relative fluorescent intensity (= peak area) of each T-RF in Samples $i$ and $j$, respectively. The numerical analysis was carried out using

Table 1. Physical and chemical characteristics of surface marine sediments. Profiles of ignition loss (IL), acid volatile sulfide-sulfur (AVS-S) and water content were measured at depth of 0 to $2 \mathrm{~cm}$. Redox potential was measured at 0 to 2,2 to 4 and 4 to $6 \mathrm{~cm}$

\begin{tabular}{|c|c|c|c|c|c|c|c|c|}
\hline \multirow{2}{*}{\multicolumn{2}{|c|}{ Sampling location }} & \multirow{2}{*}{$\begin{array}{l}\text { Depth } \\
\text { (m) }\end{array}$} & \multicolumn{3}{|c|}{ Redox potential (mV) } & \multirow{2}{*}{$\begin{array}{c}\text { IL } \\
(\%)\end{array}$} & \multirow{2}{*}{$\begin{array}{c}\text { AVS-S } \\
\left(\mu \mathrm{mol} \mathrm{cm}{ }^{-3}\right)\end{array}$} & \multirow{2}{*}{$\begin{array}{c}\text { Water content } \\
(\%)\end{array}$} \\
\hline & & & $0-2 \mathrm{~cm}$ & $2-4 \mathrm{~cm}$ & $4-6 \mathrm{~cm}$ & & & \\
\hline Tokyo Bay & $\mathrm{S} 1$ & 15 & $212 \pm 11.8$ & $-49 \pm 21.8$ & $-52 \pm 28.3$ & $2.5 \pm 0.07$ & 2.18 & $31.0 \pm 1.7$ \\
\hline \multirow[t]{2}{*}{ Sagami Bay } & $\mathrm{S} 2$ & 1520 & $40 \pm 10.0$ & $49 \pm 19.1$ & $30 \pm 13.2$ & $11.3 \pm 0.57$ & 0.01 & $87.5 \pm 0.8$ \\
\hline & S3 & 1133 & $210 \pm 3.5$ & $162 \pm 39.9$ & $150 \pm 15.4$ & $14.6 \pm 1.56$ & 0 & $76.4 \pm 0.4$ \\
\hline Suruga Bay & $\mathrm{S} 4$ & 1290 & $345 \pm 17.8$ & $207 \pm 50.2$ & $58 \pm 29.6$ & $4.8 \pm 0.13$ & 1.12 & $50.6 \pm 5.4$ \\
\hline Nankai Trough & S5 & 4023 & $458 \pm 1.2$ & $466 \pm 22.5$ & $457 \pm 6.2$ & $8.1 \pm 1.22$ & 0 & $74.1 \pm 0.3$ \\
\hline
\end{tabular}
depths. The profiles represent the mean \pm SD of 3 separate measurements. Level of AVS-S was determined from a single measurement 
BioCLUST (Iwasaki \& Hiraishi 1998). The algorithm for the neighbor-joining (NJ) method (Saitou \& Nei 1987) was used to construct dendrograms based on $D$ matrix data. Dendrograms were drawn by using the TreeView program (Page 1997).

\section{RESULTS}

\section{Physical and chemical characteristics of marine sediments}

The physical and chemical characteristics of marine sediments are listed in Table 1.

Although water depth differs widely between Tokyo Bay (S1: $15 \mathrm{~m}$ ) and Suruga Bay (S4: $1290 \mathrm{~m})$, the sediment samples from these locations had several physical and chemical characteristics in common. The redox gradient occurred between 0 and $4 \mathrm{~cm}$ depth (from $212 \pm 11.8$ to $-49 \pm 21.8 \mathrm{mV}$ ) at $\mathrm{S} 1$ and between 0 and $6 \mathrm{~cm}$ depth (from $345 \pm 17.8$ to $58 \pm 29.6 \mathrm{mV}$ ) at S4. The sediment samples from S1 and S4 included fine sands. As a result, low IL (2.5 to $4.8 \%$ ) and low water contents (31.0 to $50.6 \%$ ) were observed. The acid volatile sulfide-sulfur (AVS-S) was detected both areas (1.12 to $2.18 \mu \mathrm{mol} \mathrm{cm}^{-3}$ ). In contrast, Sagami Bay (S2 and S3), and Nankai Trough (S5) had several physical and chemical characteristics in common, such as high IL ( 8.1 to $14.6 \%$ ), high water content ( 74.1 to $87.5 \%$ ), and low AVS-S concentrations ( 0 to $0.01 \mu \mathrm{mol} \mathrm{cm}{ }^{-3}$ ) compared with S1 and S4.

\section{T-RFLP analysis}

The size of terminal-restriction fragments (T-RFs) was estimated with an automated DNA sequencer. Minimum fragment size was determined as $37 \mathrm{bp}$ and maximum fragment size as $683 \mathrm{bp}$, in accordance with the detection limits of the DNA sequencer.

A gel image of the T-RFs from HhaI, RsaI and MspIdigested 16S rDNAs is shown in Fig. 2. The 3 restriction enzymes used in this study provided about 20 to $80 \mathrm{~T}-\mathrm{RF}$ s for analysis. Although S1 and S4 displayed individual community profiles, S2, S3 and S5 profiles were similar.

The ribotype richness of the natural community was estimated by determining the number of unique T-RFs. The number of T-RFs did not differ markedly between the 3 restriction enzymes (Fig. 3). The average number (mean \pm SD: $\mathrm{n}=3$ ) of fragments estimated from the 3 restriction-enzyme analyses for each sampling site was S1: $74 \pm 6.2, \mathrm{~S} 2: 28 \pm 4.6, \mathrm{~S} 3: 27 \pm 6.2, \mathrm{~S} 4: 73 \pm 4.0$, and $\mathrm{S} 5: 35 \pm 2.1$. For $\mathrm{S} 1$ and $\mathrm{S} 4$, the fragment numbers were significantly higher than for S2, S3 and S5 ( $<0.01)$.

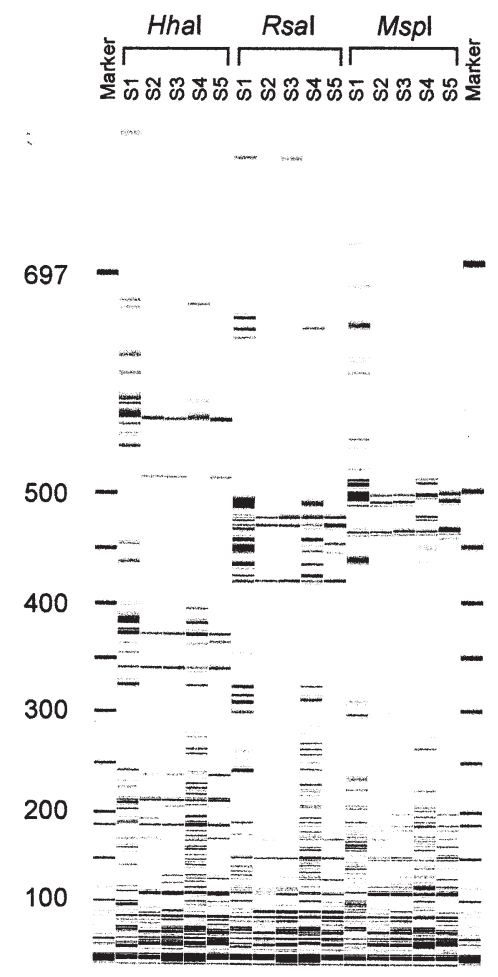

Fig. 2. Polyacrylamide gel (6\%) image of terminal-restriction fragments from total 16S rDNA digested with HhaI, RsaI and MspI, separately. Size markers are mixtures of 50 to 500 base standard (50, 100, 150, 188, 200, 250, 300, 350, 400, 450 and $500 \mathrm{bp}$ ) and PCR-amplified 16S rDNA fragment of Escherichia coli (697 bp)

The reproducibility of the T-RFLP analysis was examined by using duplicate PCR products of surface sediments from S1, S2 and S4. The differences in T-RF number between duplicates of each restriction digestion were 7 to 12 in S1, 0 to 1 in S2 and 2 to 15 in S7. These differences were only seen in T-RFs with very low peak heights $(<1.5 \%$ of maximum peak size). This high reproducibility was obtained for different PCR products, different restriction enzyme digestions and different gels.

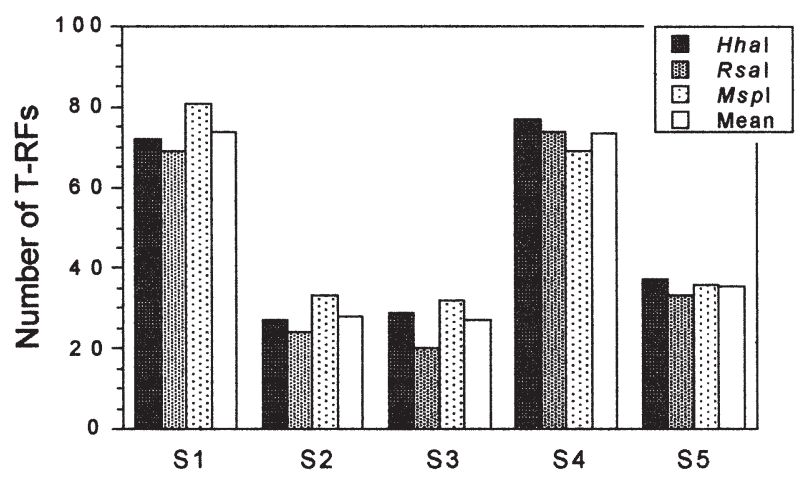

Fig. 3. Number of terminal-restriction fragments (T-RFs) from total 16S rDNA digested with HhaI, RsaI and MspI, separately 
Table 2. Relative composition of major terminal-restriction fragments (T-RFs) digested by HhaI. T-RFs that have peak areas greater than $5 \%$ of total areas at least 1 sampling site are listed. Phylogenetic group deduced from 16S rDNA clone library analysis of S1 sediment (Urakawa et al. 2000). nd: not determined; clone corresponded to this peak was not detected in the clone library constructed from S1

\begin{tabular}{|lccccccl|}
\hline Peak & $\begin{array}{c}\text { Fragment } \\
\text { size (bp) }\end{array}$ & S1 & S2 & S3 & S4 & S5 & Phylogenetic group \\
\hline A & 44 & 0.7 & 25.9 & 29.9 & 15.75 & 30.1 & nd \\
B & 52 & 0.6 & 1.6 & 6.3 & 2.8 & 8.8 & nd \\
C & 60 & 0.7 & 18 & 15 & 1.6 & 10.8 & Sulfur-oxdizing bacteria \\
D & 64 & 2 & 0 & 2.4 & 11 & 0.7 & nd \\
E & 81 & 1 & 4.3 & 8.1 & 13.1 & 7.9 & nd \\
F & 95 & 8.6 & 0 & 0 & 2.2 & 0 & Sulfate-reducing bacteria \\
G & 110 & 0 & 32.8 & 23.7 & 8.9 & 18.4 & nd \\
H & 188 & 0 & 1.3 & 0.9 & 6.5 & 1.1 & nd \\
I & 374 & 14.6 & 1 & 0.9 & 5.9 & 1.1 & Enterobacteriaceae \\
J & 384 & 13.1 & 0 & 0 & 0.9 & 0 & Vibrio spp. \\
K & 571 & 5.5 & 0 & 0 & 0 & 0 & Green non-sulfur bacteria \\
\hline
\end{tabular}

T-RFs that constituted $5 \%$ of the total peak area for any 1 sampling site are listed in Table 2. Eleven peaks satisfied this criterion, comprising $46.8 \%$ (S1), $84.9 \%$ (S2), $87.2 \%$ (S3), $68.7 \%$ (S4), and $78.9 \%$ (S5) of the total peak areas. We had previously constructed a $16 \mathrm{~S}$ rDNA clone library from the sediment sample of S1 and determined which peaks corresponded to which clones (Urakawa et al. 2000). We were thus able to perform peak identification, and 5 peaks were identified (Table 2). Peak C, corresponding to the sulfur-oxidizing bacteria, was detected in all samples, and comprised a large fraction of S2, S3 and S5. In contrast, Peak F, corresponding to the sulfate-reducing bacteria, comprised $8.6 \%$ of the composition of $\mathrm{S} 1$ and was also detected in S4 (2.2\%). Peak I, corresponding to Enterobacteriaceae, comprised $13.1 \%$ of $\mathrm{S} 1$ (14.6\%) and was also detected in S4 (5.9\%). Peak J, corresponding to Vibrio spp., comprised $13.1 \%$ of $\mathrm{S} 1$ and was also detected in S4 $(0.9 \%)$. This peak was known to consist solely of Vibrio spp. because the 16S rRNA gene of many Vibrio spp. includes an unusual insertion, which constitutes a marker distinguishing Vibrio spp. from other bacterial groups. Peak K, corresponding to green non-sulfur bacteria, was only detected in S1 (5.5\%).

\section{Quinone profiling}

The quinone profiles obtained from the marine sediments were affected by the relative abundance of each homolog (Fig. 4). However, homolog number did not change between sampling sites. Sixteen quinone homologs were detected for S2, S3, S4 and S5, 17 quinone homologs were found for $\mathrm{S} 1$. The appearance and disappearance of quinone homologs occured only in minor components. MK-11 and MK-9 $\left(\mathrm{H}_{2}\right)$ were only found in S1. MK-11 $\left(\mathrm{H}_{2}\right)$ was only found from S2, S3 and S5. The quinone homologs obtained in this study were compared with data from activated sludge (Hiraishi et al. 1998): 5 quinone homologs, PQ-9, MK$6\left(\mathrm{H}_{2}\right), \mathrm{MK}-11\left(\mathrm{H}_{2}\right), \mathrm{MMK}-7$ and MMK-8, were present only in the marine sediment samples, and these homologs are therefore regarded as representative of marine sediments. Major quinone homologs differed among sampling locations. Five major quinones, UQ-8, PQ-9, MK-7, MK-8, and methylmenaquinone-7 (MM $\mathrm{K}-7)$ were the predominant components in S1. In Sagami Bay (S2 and S3), both sediments showed relatively similar profiles and MMK-7 was the major component. MK-6 was the major component in S4, while MMK-8 and MK-8 were the dominant components in S5.

Chemotaxonomic studies have shown that the major component of quinone differs among the various bacterial lineages (Iwasaki \& Hiraishi 1998). This fact enabled us to estimate the specific origins of the quinone homologs. It was assumed that UQs were mainly derived from $\alpha, \beta$, and $\gamma$-Proteobacteria (Yokota et al. 1992) (Fig. 4). The marine sediments contained large amount of MKs, which comprised 60 to $74 \%$ of the total quinones. The source of the MKs was considered to be bacterial groups such as the low-GC Gram-positive bacteria (MK-6 to MK-8), most $\delta$ and $\varepsilon$-Proteobacteria (MK-6 and MK-7), Cytophaga-Flavobacterium (MK-6 and MK-7) spp. and Planctomyces (MK-6) spp. (Collins \& Jones 1981, Carlone \& Anet 1983, Collins \& Widdel 1986, Nakagawa \& Yamasato 1993, Sittig \& Schlesner 1993). It was assumed that MK-7 to MK-11, and MK-9 $\left(\mathrm{H}_{2}\right)$, MK-9 $\left(\mathrm{H}_{4}\right)$, MK-9 $\left(\mathrm{H}_{8}\right)$, MK-10 $\left(\mathrm{H}_{4}\right)$ and MK-11 $\left(\mathrm{H}_{2}\right)$ were derived from Actinobacteria (Yokota 1999).

The $M K / U Q$ ratio, $M D q$ and $B D q$ values are listed in Table 3. The quinone component of marine sediments showed a relatively high MK/UQ ratio (2.66 to 4.78 ) 

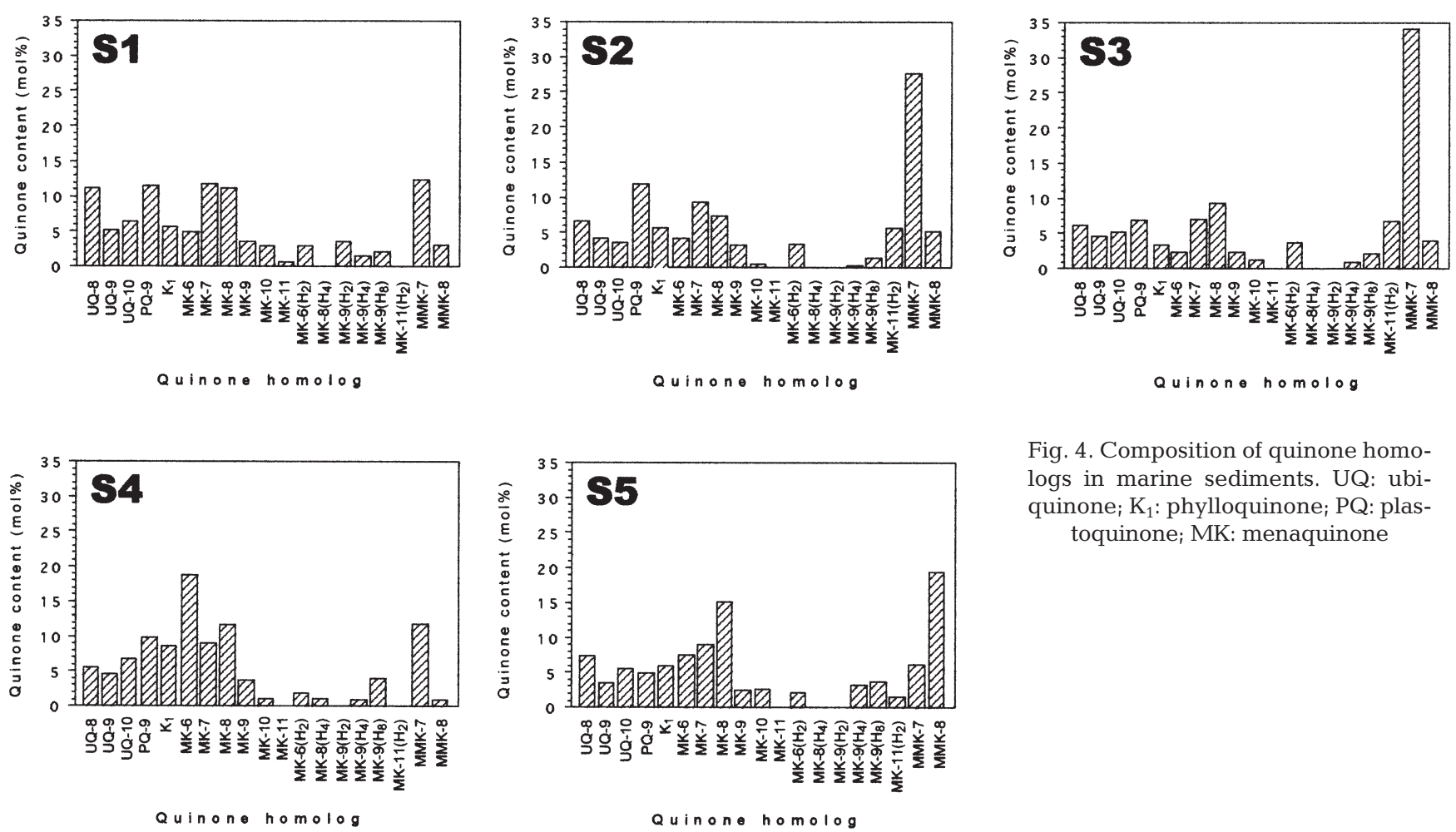

Fig. 4. Composition of quinone homologs in marine sediments. UQ: ubiquinone; $\mathrm{K}_{1}$ : phylloquinone; $\mathrm{PQ}$ : plastoquinone; $\mathrm{MK}$ : menaquinone

compared to that of activated sludge samples (0.455 to 0.981) (Hiraishi et al. 1998). The $M D q$ values, which indicate the microbial divergence and balance of samples, ranged between 12.95 and 14.99 among the marine sediment samples (Hiraishi et al. 1998). These values were similar to results from raw-sewage activated sludges (between 12.28 to 13.15), higher than those for raw sewage (between 7.11 and 10.66), sewage mats (9.33), synthetic sewage activated sludge (between 7.23 and 13.25), river water (between 7.75 and 8.68), and lake water (9.43), but were lower than that for a soil sample (16.82) (Iwasaki \& Hiraishi 1998). The $B D q$ value reflects the divergence of bioenergetic models of microbes (i.e., the balance of UQ-mediated aerobic respiration, oxygenic photosynthesis, and anaerobic and/or MK-mediated aerobic respiration) (Iwasaki \& Hiraishi 1998, Hiraishi et al. 1999). The BDq

Table 3. MK/UQ ratio and, $M D q$ and $B D q$ values for marine sediments. MK/UQ: menaquinone/ubiquinone ratio; $M D q$ : microbial divergence; $B D q$ : bioenergetic divergence

\begin{tabular}{|lccc|}
\hline Sediment & MK/UQ & $M D q$ & $B D q$ \\
\hline S1 & 2.66 & 14.99 & 2.77 \\
S2 & 4.78 & 13.06 & 2.63 \\
S3 & 4.62 & 12.95 & 2.49 \\
S4 & 3.85 & 13.42 & 2.70 \\
S5 & 4.45 & 14.21 & 2.52 \\
\hline
\end{tabular}

value ranged between 2.49 and 2.77 in marine sediment samples. These values were higher than those for sulfur-turf mats (1.18 to 1.37 ) and a soil sample (1.83), but were almost the same as those for river water samples (2.49 to 2.56) and cyanobacterial mats (2.20 to 2.67) (Iwasaki \& Hiraishi 1998, Hiraishi et al. 1999).

\section{Cluster analysis}

The $D$ value deduced from T-RFLP was relatively greater than that produced by quinone profiling (Tables 4 \& 5). A close relationship was observed between the Sagami Bay sediments (S2 and S3), and the Nankai Trough sediment (S5) (16.8 to 25.8\% diver-

Table 4. $D$ value matrix deduced from T-RFLP analysis of the marine sediments. The $D$ value (dissimilarity) of T-RFLP analysis was calculated from the difference in the relative fluorescent intensity ( $=$ peak area) of each terminal-restriction fragment between 2 marine sediments

\begin{tabular}{|lccccc|}
\hline Sediment & S1 & S2 & S3 & S4 & S5 \\
\hline S1 & 0 & & & & \\
S2 & 90.4 & 0 & & & \\
S3 & 88.5 & 20.2 & 0 & & \\
S4 & 72.3 & 59.8 & 53.4 & 0 & \\
S5 & 89.9 & 25.8 & 16.8 & 54.4 & 0 \\
\hline
\end{tabular}


Table 5. $D$ value matrix deduced from quinone profiling of marine sediments. The $D$ value (dissimilarity) of the quinone profile was calculated from the difference in the level of each quinone homolog $(\mathrm{mol} \%)$ between 2 marine sediments

\begin{tabular}{|lccccc|}
\hline Sediment & S1 & S2 & S3 & S4 & S5 \\
\hline S1 & 0 & & & & \\
S2 & 24.1 & 0 & & & \\
S3 & 30.2 & 13.9 & 0 & & \\
S4 & 20.8 & 30.8 & 34.7 & 0 & \\
S5 & 28.1 & 35.6 & 37.7 & 29.5 & 0 \\
\hline
\end{tabular}

gences) (Table 4). The $D$ value matrix from the quinone profiling revealed, the highest similarity to be between the Sagami Bay sediments (S2 and S3) (13.9\% divergence) (Table 5). The reproducibility of the quinone analysis, tested using triplicate samples, was $\pm 5 \%$. Dendrograms based on the $D$ value matrices from both methods are shown in Fig. 5. Sagami Bay sediments (S2 and S3) and Nankai Trough sediment (S5) were tightly clustered in the T-RFLP analysis (Fig. 5A). Quinone profiling showed Sagami Bay sediments (S2 and S3) to be closely related, but the position of $\mathrm{S} 5$ on the quinone profile dendrogram differed completely from that shown by T-RFLP analysis (Fig. 5B).

\section{DISCUSSION}

Liu et al. (1997) used the T-RFLP technique on 4 different, complex, communities and reported that there were $21,33,33$, and 36 different T-RFs in activated sludge, enriched sludge from a laboratory scale bioreactor, aquifer sand, and gut DNA of termite samples, respectively when the PCR products were digested by HhaI. Moeseneder et al. (1999) reported that the T-RF number of seawater samples ranged from 26 to 58 when the PCR products were digested with $\mathrm{CfoI}$ (= HhaI). The range of T-RFs obtained in the present study was greater than that found in previous studies (Liu et al. 1997, Moeseneder et al. 1999). We therefore infer that marine sediments probably have a larger range of ribotype diversity.

Although T-RFLP analysis is useful for estimating the phylogenetic diversity and composition of complex communities in various environments, microbial diversity may be underestimated due to inherent biases associated with this molecular technique. In general, some peaks from T-RFLP with 4-cutter enzymes represent species, while others represent wide groups, and others still may represent mixtures of unrelated organisms. Peak I in the present study was identified as Enterobacteriaceae (which are usually regarded as being
A

B

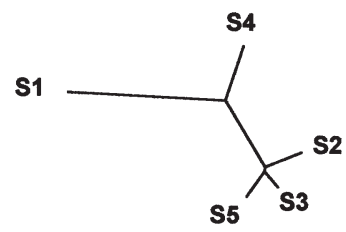

$\overline{0.1}$

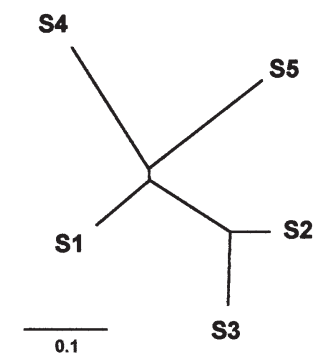

Fig. 5. Neighbor-joining dendrograms based on $D$ value matrix data from T-RFLP analysis (A) and quinone profiling (B). Bars indicate $10 \%$ divergence ( $D$-index value)

of terrestrial origin) from a clone library (Urakawa et al. 2000) constructed from a sediment sample from $\mathrm{S} 1$; this peak was also found for samples from S4 (Table 2). Although river flows probably transport terrestrial microorganisms to coastal sediments, they are unlikely to strongly affect deep-sea sediments (Urakawa et al. 2000). Therefore, the sources of Peak I may differ between S1 and S4. A further bias arises because some microbial populations are not detected by T-RFLP analysis, i.e. when the fragment size falls outside the range of the T-RFLP standards. It is also possible that in some sequences the restriction site is immediately next to the primer site on the electropherograms, with the result that they are cut too short for analysis. Other sequences display no cutting position whatsoever. As a result, the T-RF number is underestimated. To avoid such bias, it is necessary to select a suitable primer pair and suitable restriction enzymes for T-RFLP analysis. We used the primer pair 8 and 926r for T-RFLP analysis because this pair has been shown to produce large number of unique $5^{\prime} \mathrm{T}$-RFs after in silico prediction of restriction digestion with HhaI or MspI (Liu et al. 1997). A small number of peaks was detected in a fraction $>675 \mathrm{bp}$ in the computer simulation by using $8 \mathrm{f}$ and 926r (Liu et al. 1997). In the present study, a small number of peaks ( 0 to 8 ), corresponding to $<11 \%$ of the fragment number, was included in a fraction $>697 \mathrm{bp}$, and no cutting site fragment (corresponding to $919 \mathrm{bp}$ ) was observed. Therefore, this bias may have no strong effect in this study.

Hiraishi et al. (1998) reported that UQs and MKs are usually present at MK/UQ ratios of 0.6 to 1.0 in municipal sewage activated sludges. Quinone components of marine sediments showed higher MK/UQ ratios (2.66 to 4.78 ) than activated sludge samples (Table 3). In activated sludges, the amount of UQs represent more than $40 \%$ of the total quinones, a larger proportion than that of marine sediments (between 14 and $23 \%$ : Fig. 4) (Hiraishi et al. 1998). In marine sediments, the 
minimum MK/UQ ratio (2.66) was observed in coastal sediment from Tokyo Bay (S1), and much larger MK/UQ ratios were obtained from deep-sea sediments (3.85 to 4.78) (Table 3). Hedrick \& White (1986) reported the same phenomenon: i.e. quinone profiles from the deep-sea surface sediments differing greatly from profiles of estuarine sediments, and with a much smaller proportion of UQs. Therefore, the MK/UQ ratio could be a useful indicator for assessing microbial communities in marine sediments.

Another important finding was that we detected considerable ratios of $K_{1}$ and PQ-9 not only from coastal but also from deep-sea sediment samples (10.3 to 17.6\%: Fig. 4). These quinones are essential mediators of oxygenic photosynthetic electrotransport in cyanobacteria and chloroplasts (Hiraishi et al. 1999). It is known that sinking particles derived from phytoplankton are the major food source for benthic animals on deep-sea sediments (Billett et al. 1983). Cyanobacteria displaying growth activity have been found at a depth of $4500 \mathrm{~m}$ in marine sediments (Lochte \& Turley 1988). Therefore, we inferred that the $\mathrm{K}_{1}$ and PQ-9 detected in the deep-sea sediments originated from sinking particles emanating from cyanobacteria or other eukaryal phytoplankton. Our findings indicate that $\mathrm{K}_{1}$ and PQ-9 could be new biomarkers for the study of the rapid primary-production transport pathway for benthic animals (Billett et al. 1983).

Marine sediments from Tokyo Bay (S1) and Suruga Bay (S4) had several common physical and chemical characteristics. Steep redox gradients were present in $\mathrm{S} 1$ and S4 but not in S2, S3 and S5 (Table 1). In general, steep gradients provide niches for a wide variety of metabolically diverse microorganisms (Fenchel \& Finlay 1995). The number of T-RFs was significantly higher in S1 and S4 than in S2, S3 and S5.

A similarity of the microbial communities in Sagami Bay (S2 and S3) and Nankai Trough (S5) was revealed by both techniques. T-RFLP analysis characterized Sagami Bay (S2 and S3) and Nankai Trough (S5) as low ribotype-richness areas (Fig. 3). The gel images of S2, S3 and S5 were similar, and this congruity was obtained in 3 different restriction-enzyme patterns (Fig. 2). Moyer et al. (1996) tested in silico prediction of restriction digestion for their 16S rRNA data set and concluded that a combination of more than 3 restriction enzymes gave good resolution based on phylogeny. Thus, we presumed that the major phylogenetic groups in the 3 different sampling sites (S2, S3 and S5) were similar, since the T-RF profiles produced by 3 separate restriction digestions were almost identical (Fig. 2). These similarities were observed not only in fragment patterns, but also in major peak abundance (Table 2). Samples from Sagami Bay (S2 and S3) and Nankai Trough (S5) had 2 extremely large peaks,
A and G. Both peaks comprised 58.7, 53.6 and $48.5 \%$ of all components in the S2, S3 and S5 sediments, respectively. These peaks were mostly undetected in S1. We could not identify these peaks, but their distribution pattern in the sediment samples was similar to the pattern of Peak C, which corresponds to sulfuroxidizing bacteria.

The predominant quinone components differed between Sagami Bay (S2 and S3) and Nankai Trough (S5): MMK-7 and MMK-8 were the major components in Sagami Bay and Nankai Trough, respectively. These quinones comprised a considerable amount of the components in these locations (Fig. 4). It is known that some $\delta$ and $\varepsilon$-Proteobacteria and a few $\gamma$-Proteobacteria, such as Shewanella spp. could be sources of MMKs (Carlone \& Anet 1983, Itoh et al. 1985). The genus Shewanella is composed of an ecologically diverse group of aerobic or facultative anaerobic, Gram-negative Proteobacteria isolates of both marine and terrestrial origin (MacDonell et al. 1985, Deming et al. 1988, Lonergan et al. 1996, Kato et al. 1998, Urakawa et al. 1999b). DeLong et al. (1997) reported that $S$. benthica is the most commonly isolated barophilic species, being recovered from a variety of deep-sea environments. Arcobacter spp. (belonging to the $\varepsilon$-Proteobacteria) was considered as another possible source of MMKs because members of this genus have recently been detected in marine sediments (Llobet-Brossa et al. 1998, Li et al. 1999). Therefore, both T-RFLP and quinone profiling inferred that the presence of some unknown major bacterial groups predominated in S2, S3 and S5. Further phylogenetic studies and functional analyses are required to clarify these bacterial groups.

Neighbor-joining dendrograms revealed a contradiction in the position of S5 between T-RFLP analysis and quinone profiling (Fig. 5). It was assumed that this difference derived from different characteristics of the 2 techniques. T-RFLP analysis can detect population changes based on 16S rDNA, but is not free from many biases, such as differences in gene copy number between species, DNA extraction and PCR amplification (Amann et al. 1995).

On the other hand, quinone profiling can detect not only the population structure but also the energy metabolism and metabolic activity of the microbial community. Thus, we found that the microbial population observed in S2, S3, and S5 were phylogenetically similar, but that the abundance and physiological condition of each microorganism apparently differ between the Sagami Bay samples (S2 and S3) and the Nankai Trough sample (S5).

More detailed understanding of the 2 different fingerprint techniques may be helpful for the interpretation of future investigations. The combined method of T-RFLP analysis and quinone profiling reflects differ- 
ent aspects of the microbial community, and is likely to provide an effective approach to the analysis of microbial communities in marine sediments.

Acknowledgements. We greatly thank Akira Hiraishi (Toyohashi University of Technology, Japan) for his valuable cooperation for quinone analysis. We are grateful to the captain and crew of the RV 'Tansei-Maru' for their skillful help in sampling. We are indebted to Theodore J. MacDonald and Uffe Thomsen (University of Southern Denmark) for critical reading of this manuscript.

\section{LITERATURE CITED}

Amann RI, Ludwig W, Schleifer K-H (1995) Phylogenetic identification and in situ detection of individual microbial cells without cultivation. Microbiol Rev 59:143-169

Avaniss-Aghajani E, Jones K, Chapman D, Brunk C (1994) A molecular technique for identification of bacteria using small subunit ribosomal RNA sequences. BioTechniques 17:144-149

Billett DSM, Lampitt RS, Rice AL, Mantoura RFC (1983) Seasonal sedimentation of phytodetritus to the deep-sea benthos. Nature (Lond) 302:520-522

Carlone GM, Anet FAL (1983) Detection of menaquinone-6 and a novel methyl-substituted menaquinone- 6 in Campylobacter jejuni and Campylobacter fetus subsp. fetus. J Gen Microbiol 129:3385-3393

Coastal Oceanography Research Committee, The Oceanographical Society of Japan (1985) Coastal Oceanography of Japanese Islands. Tokai University Press, Tokyo

Collins MD, Jones D (1981) Distribution of isoprenoid quinone structural types in bacteria and their taxonomic implications. Microbiol Rev 45:316-354

Collins MD, Widdel F (1986) Respiratory quinones of sulphate-reducing and sulphur-reducing bacteria: a systematic investigation. Syst Appl Microbiol 8:8-18

DeLong EF, Franks DG, Yayanos AA (1997) Evolutionary relationships of cultivated psychrophilic and barophilic deep-sea bacteria. Appl Environ Microbiol 63:2105-2108

Deming JW, Somers LK, Straube WL, Swartz DG, MacDonell MT (1988) Isolation of an obligately barophilic bacterium and description of a new genus, Colwellia gen. nov. Syst Appl Microbiol 10:152-160

Fenchel T, Finlay BJ (1995) Ecology and evolution in anoxic worlds. Oxford University Press, New York

Findlay RH, Watling L (1998) Seasonal variation in the structure of a marine benthic microbial community. Microb Ecol 36:23-30

Giovannoni SJ, Britschgi TB, Moyer CL, Field KG (1990) Genetic diversity in Sargasso Sea bacterioplankton. Nature 345:60-63

Gray JP, Herwig RP (1996) Phylogenetic analysis of the bacterial communities in marine sediments. Appl Environ Microbiol 62:4049-4059

Hedrick DB, White DC (1986) Microbial respiratory quinones in the environment. I. A sensitive liquid chromatographic method. J Microbiol Methods 5:243-254

Hiraishi A, Ueda Y, Ishihara J, Mori T (1996) Comparative lipoquinone analysis of influent sewage and activated sludge by high-performance liquid chromatography and photodiode array detection. J Gen Appl Microbiol 42: 457-469

Hiraishi A, Ueda Y, Ishihara J (1998) Quinone profiling of bac- terial communities in natural and synthetic sewage activated sludge for enhanced phosphate removal. Appl Environ Microbiol 64:992-998

Hiraishi A, Umezawa T, Yamamoto H, Kato K, Maki Y (1999) Changes in quinone profiles of hot spring microbial mats with a thermal gradient. Appl Environ Microbiol 65: 198-205

Itoh T, Funabashi H, Katayama-Fujimura Y, Iwasaki S, Kuraishi $H$ (1985) Structure of methylmenaquinone-7 isolated from Alteromonas putrefaciens IAM 12079. Biochim Biophys Acta 840:51-55

Iwasaki M, Hiraishi A (1998) A new approach to numerical analyses of microbial quinone profiles in the environment. Microbes Environ 13:67-76

Jørgensen BB (1982) Mineralization of organic matter in the sea bed-the role of sulphate reduction. Nature 296: 643-645

Kato C, Li L, Nogi Y, Nakamura Y, Tamaoka J, Horikoshi K (1998) Extremely barophilic bacteria isolated from the Mariana Trench, Challenger Deep, at a depth of 11000 meters. Appl Environ Microbiol 64:1510-1513

Kemp WM, Boynton WR (1992) Benthic-pelagic interactions: nutrient and oxygen dynamics. In: Smith DE, Leffler M, Mackiernan G (eds) Oxygen dynamics in the Chesapeake Bay. Maryland Sea Grant, College Park, p 149-221

Kröger A (1978) Determination of contents and redox states of ubiquinone and menaquinone. Methods Enzymol 53: $579-591$

Lane DJ (1991) 16S/23S rRNA sequencing. In: Stackebrandt E, Goodfellow M (eds) Nucleic acid techniques in bacterial systematics. John Wiley \& Sons, New York, p 115-148

Li L, Kato C, Horikoshi K (1999) Microbial diversity in sediments collected from the deepest cold-seep area, the Japan Trench. Mar Biotechnol 1:391-400

Liu WT, Marsh TL, Cheng H, Forney LJ (1997) Characterization of microbial diversity by determining terminal-restriction fragment length polymorphisms of genes encoding 16S rRNA. Appl Environ Microbiol 63:4516-4522

Llobet-Brossa E, Rosselló-Mora R, Amann R (1998) Microbial community composition of Wadden Sea sediments as revealed by fluorescence in situ hybridization. Appl Environ Microbiol 64:2691-2696

Lochte K, Turley CM (1988) Bacteria and cyanobacteria associated with phytodetritus in the deep sea. Nature 333:67-69

Lonergan DJ, Jenter HL, Coates JD, Phillips EJP, Schmidt TM, Lovley DR (1996) Phylogenetic analysis of dissimilatory Fe(III)-reducing bacteria. J Bacteriol 178:2402-2408

MacDonell MT, Colwell RR (1985) Phylogeny of the Vibrionaceae and recommendation for two new genera, Listonella and Shewanella. Syst Appl Microbiol 6:171-182

Marsh TL, Liu WT, Forney LF, Cheng H (1998) Beginning a molecular analysis of the eukaryal community in activated sludge. Water Sci Technol 37:455-460

Moeseneder MM, Arrieta JM, Muyzer G, Winter C, Herndl GJ (1999) Optimization of terminal-restriction fragment length polymorphism analysis for complex marine bacterioplankton communities and comparison with denaturing gradient gel electrophoresis. Appl Environ Microbiol 65: 3518-3525

Moyer CL, Tiedje JD, Dobbs FC, Karl DM (1996) A computersimulated restriction fragment length polymorphism analysis of bacterial small-subunit rRNA genes: efficacy of selected tetrameric restriction enzymes for studies of microbial diversity in nature. Appl Environ Microbiol 62: 2501-2507

Muyzer G, de Waal EC, Uitterlinden AG (1993) Profiling of complex microbial populations by denaturing gradient gel 
electrophoresis analysis of polymerase chain reactionamplified genes coding for 16S rRNA. Appl Environ Microbiol 59:695-700

Nakagawa Y, Yamasato K (1993) Phylogenetic diversity of the genus Cytophaga revealed by $16 \mathrm{~S}$ rRNA sequencing and menaquinone analysis. J Gen Microbiol 139:1155-1161

Novitsky JA (1983) Heterotrophic activity throughout a vertical profile of seawater and sediment in Halifax Harbor, Canada. Appl Environ Microbiol 45:1753-1760

Novitsky JA (1990) Evidence for sedimenting particles as the origin of the microbial community in a coastal marine sediment. Mar Ecol Prog Ser 60:161-167

Pace NR, Stahl DA, Lane DJ, Olsen GJ (1986) The analysis of natural microbial populations by ribosomal RNA sequences. Adv Microb Ecol 9:1-55

Page RDM (1997) TreeView. Version 1.5. University of Glasgow, Glasgow

Osborn AM, Moore ERB, Timmis KN (2000) An evaluation of terminal-restriction fragment length polymorphism (T-RFLP) analysis for the study of microbial community structure and dynamics. Environ Microbiol 2:39-50

Rajendran N, Matsuda O, Imamura N, Urushigawa Y (1992) Variation in microbial biomass and community structure in sediments of eutrophic bays as determined by phospholipid ester-linked fatty acids. Appl Environ Microbiol 58: 562-571

Ravenschlag K, Sahm K, Pernthaler J, Amann R (1999) High bacterial diversity in permanently cold marine sediments. Appl Environ Microbiol 65:3982-3989

Editorial responsibility: Otto Kinne (Editor),

Oldendorf/Luhe, Germany
Saitou N, Nei M (1987) The neighbor-joining method: a new method for reconstructing phylogenetic trees. Mol Biol Evol 4:406-425

Sittig M, Schlesner H (1993) Chemotaxonomic investigation of various prosthecate and/or budding bacteria. Syst Appl Microbiol 16:92-103

Ueda T, Suga Y, Matsuguchi T (1995) Molecular phylogenetic analysis of a soil microbial community in a soybean field. Eur J Soil Sci 46:415-421

Urakawa H, Kita-Tsukamoto K, Ohwada K (1999a) Microbial diversity in marine sediments from Sagami Bay and Tokyo Bay, Japan, as determined by 16S rRNA gene analysis. Microbiology (NY) 145:3305-3315

Urakawa H, Kita-Tsukamoto K, Ohwada K (1999b) 16S rDNA restriction fragment length polymorphism analysis of psychrotrophic vibrios from Japanese coastal water. Can J Microbiol 45:1001-1007

Urakawa H, Yoshida T, Nishimura M, Ohwada K (2000) Characterization of depth-related population variation in microbial communities of a coastal marine sediment using 16S rDNA-based approaches and quinone profiling. Environ Microbiol 2:542-554

Yokota A (1999) Taxonomic significance of morphological and chemotaxonomic characteristics and phylogeny in Grampositive bacteria. Microbes Environ 14:25-30

Yokota A, Akagawa-Matsushita M, Hiraishi A, Katayama Y, Urakami T, Yamasato K (1992) Distribution of quinone systems in microorganisms: Gram-negative eubacteria. Bull Jpn Fed Culture Collection 8:136-171

Submitted: February 28, 2000; Accepted: October 17, 2000

Proofs received from author(s): September 4, 2001 